\title{
Effect of Muscle Energy Technique on Piriformis Tightness in Chronic Low Back Pain with Radiation
}

\author{
Mitushi Kishor Deshmukh¹, Pratik Arun Phansopkar², Kiran Kumar³ \\ 1,2,3 Department of Musculoskeletal Physiotherapy, Ravi Nair Physiotherapy College, \\ Datta Meghe Institute of Medical Sciences, Wardha, Maharashtra, India.
}

\section{ABSTRACT}

\section{BACKGROUND}

Low back pain is a common condition in India. $90 \%$ of Indian population experience low back pain at least once in their lifetime. Studies show that $98 \%$ low back pain is because of mechanical disorder of spine. Piriformis tightness is one of the most misdiagnosed causes for low back pain or sacroiliac joint dysfunction. Various manual therapy approaches have been studied for reducing muscle tightness. We wanted to assess the effectiveness of muscle energy technique that is post-isometric relaxation technique on piriformis muscle tightness, its effectiveness in relieving low back pain with radiation, and increasing range of motion.

\section{METHODS}

60 patients were included in the study as per inclusion and exclusion criteria from Ravi Nair Physiotherapy College, Sawangi Meghe, and were randomly assigned in to two groups. The duration of study was 12 days ( 6 sessions / week) and follow up was taken on $27^{\text {th }}$ day. Subjects in muscle energy technique experimental group were treated with post isometric relaxation technique (PIR), subjects in control group were given simple passive stretching of piriformis. All subjects were educated about proper ergonomics.

\section{RESULTS}

Both interventions post isometric relaxation and simple stretching techniques were effective in terms of pain reduction, ROM (Range of Motion) improvement, piriformis tightness, disability with $\mathrm{p}<0.05$ with post isometric relaxation technique superseding simple stretching. Moreover, post isometric relaxation technique in muscle energy technique had sustained effects on follow-up in terms of relieving pain, disability and tightness for longer period of time.

\section{CONCLUSIONS}

Muscle energy technique gives immediate relief of pain improving ROM and decreasing tightness of piriformis and disability and has longer lasting effects.
Corresponding Author: Dr. Pratik Arun Phansopkar, Assistant Professor,

Department of Musculoskeletal Physiotherapy, Ravi Nair Physiotherapy College, Datta Meghe Institute of Medical Sciences, Wardha, Maharashtra India.

E-mail:drpratik77@gmail.com

DOI: $10.14260 / \mathrm{jemds} / 2020 / 722$

How to Cite This Article: Deshmukh MK, Phansopkar PA, Kumar K. Effect of muscle energy technique on piriformis tightness in chronic low back pain with radiation. J Evolution Med Dent Sci 2020;9(44):3284-3288, DOI: $10.14260 / \mathrm{jemds} / 2020 / 722$

Submission 27-07-2020,

Peer Review 22-09-2020

Acceptance 28-09-2020,

Published 02-11-2020.

Copyright (C) 2020 Mitushi Kishor Deshmukh et al. This is an open access article distributed under Creative Commons Attribution License [Attribution 4.0 International (CC BY 4.0)]

\section{KEY WORDS}

Piriformis Tightness, Muscle Energy Technique, Stretching. 


\section{BACKGROUND}

Piriformis Syndrome (PS) is among the most misdiagnosed causes of lumbosacral or low back pain due to its nonspecific diagnostic technique and it can mimic other problems such as disc herniation which is also present with leg pain.

PS can occur due to any abnormalities as for example tightness, spasm, hypertrophy or tenderness of this muscle. Piriformis muscle anatomic variation can result in sciatic nerve compression. The rate of incidence of PS in patients with low back pain is $5 \%-36 \%{ }^{1}$ Piriformis syndrome is more popular amongst women than men with a ratio of $6: 1 .^{2}$ The muscle has been innerved by L5, S1-2 branches. $^{3}$ Piriformis works as an external rotator and abductor when we flex the thigh to 60 degrees. The piriformis muscle is in close connection with both to the sacroiliac joint and to the sciatic nerve. There is a variable connection among piriformis and the sciatic nerve. The sciatic nerve passes through the piriformis muscle in about 15 percent of the population, in whole or in part, rather than below it. ${ }^{1}$

Depending on cause PS is divided into two types: According to Sir Yeoman primary PS (15 \%) caused by anatomical variation in sciatic nerve. ${ }^{4}$ Secondary PS is caused by a precipitating cause, like trauma (around 50 percent) or overuse and irritates the sciatic nerve. ${ }^{5}$ Trauma to the buttock leads to period of irritation, pain-spasminflammation. The inflammation of piriformis muscle may compress the sciatic nerve. Piriformis syndrome causes chronic pain in buttock this can radiate to just below the leg in sciatic nerve distribution and worsens with walking and squatting, intolerance to sitting. ${ }^{6}$ Hence it is always confusing with sciatica which is due to disc pathologies. ${ }^{7}$ Researchers at Ceders Sinai medical centre and institute of nerve medicine in Los Angeles found that those patients whose symptoms had not improved after treatment of herniated disc found about $69 \%$ patient had PS.

Patient always compliant of pain deep in buttock, so PS is also referred as deep buttock syndrome. Patient may also have difficulty in walking. Patients can complain of foot numbness, abdominal, inguinal and pelvic pain and intestinal pain. Dyspareunia can be seen in women hence it is always confused with sciatica. ${ }^{8}$ Therefore, PS primarily requires a systematic history that is scientifically established, and a rigorous physical examination plays significant role. Tenderness in the region of sacroiliac joint, greater sciatic notch, and piriformis muscle are possible findings in a patient with PS. Studies on low back pain shows that lordosis may be exaggerated due to piriformis spasm. ${ }^{9}$

Normal PS control care plan involves both surgical (piriformis surgical release and sciatic nerve decompression) and non-surgical (pharmacological and therapeutic) measures. ${ }^{10}$ Medical management include tapering oral steroids, non-steroidal anti-inflammatory drug, local anaesthetics dramatically reduce patients' pain. Physiotherapy include McKenzie protocol and MET (Muscular

Energy Techniques), stretching technique, extension exercises myofacial release technique and electrotherapeutic modalities like traction, TENS (Transcutaneous Electrical Nerve Stimulation), US (Ultra Sound). ${ }^{11}$

Post isometric relaxation in muscle energy technique is effective in relieving trigger point in hypertonic muscle and fibrotic changes in muscle than local anaesthesia, it is very effective in lengthening contracted or spasmodic muscle, relieving oedema and relive passive congestion. ${ }^{12}$ MET also create synergetic effect on piriformis, gluteus maximus and erector spinae in correcting position of sacrum. Piriformis tightness is a common problem seen in middle aged patients with low back pain having radiation to lower limb. Pain affects individual of all occupational and activity level so treatment is required which will reduce pain, radiation, disability in short span of time. In chronic cases of low back pain with lower limb radiation pain, the present research was to evaluate the effect of Post-Isometric Relaxation (PIR) of muscle energy technique in the treatment of piriformis tightness.

\section{METHODS}

This was a randomized controlled trial conducted at Ravi Nair Physiotherapy College, Musculoskeletal OPD. 60 subjects (95 \% CI: 1.96) $\left[\mathrm{n} 1=\left\{\left(1.96^{\wedge}\right)^{*} .4^{*} .6^{*} \mathrm{~N}\right) /\left(1.96^{\wedge} .4^{*} .6^{*}\right.\right.$ $\left.\left.\left(.03^{\wedge} 2\right)\right\}\right]$ were included in this study with the 25 to 40 year age group patients coming to OPD RNPC (Ravi Nair Physiotherapy College) and AVBRH, Sawangi Meghe Wardha. In total, 64 subjects were screened for back \& buttock pain for piriformis tightness using pace sign and Freiberg sign, of which 60 subjects were enrolled in this randomized controlled study that fulfilled the research criteria. Using the simple random sampling method via envelope method, selected patients were divided into 2 groups by allocation method. Group A, 30 patients received only moist heat, stretching of the piriformis and strengthening of the hip abductor. Group B, In MET 30 patients received PIR. Ergonomic advice was given to both groups. Treatment program consisted of, 12 days ( 6 sessions / week) over a period of two weeks. Follow up was taken on $27^{\text {th }}$ day.

\section{Inclusion Criteria}

Both male and female patients between 25 to 40 years with chronic low back pain radiating to lower limb with tight piriformis, unilateral involvement of piriformis muscle, \& positive test for piriformis i.e. Freiberg test, Sign of Pace.

\section{Exclusion Criteria}

Established spinal deformity, prolapsed intervertebral disc and pregnancy.

\section{Outcome Measures}

Visual Analogue Scale (VAS), Straight Leg Raise (SLR), Oswestry Low Back Pain Disability Index, Hip ROM, piriformis tightness.

\section{Procedure}

All the participants received informed consent form and were explained about the procedures of the study. All outcomes were assessed on first day, last day of session and on $27^{\text {th }}$ day. 


\section{Pain Intensity Assessment}

Visual analog scale was used for the assessment of pain severity (VAS is reliable and valid tool to assess pain component). ${ }^{13}$ A $10 \mathrm{~cm}$ line with numbers $0 \& 10$ where 0 symbolizes no pain and 10 is intolerable maximum pain. All patients were asked to mark their intensity of pain on VAS.

\section{SLR Test}

The patient was placed in supine position with one hand extended; leg was put under the affected side hip and another hand is put on the knee to avoid bending of the knee. With limb extended examiner places thigh on pelvis. Keeping the knee straight normally patient will have the limb extended almost $90^{\circ}$ without pain, if this manoeuvre is markedly painlimited the test is positive. The test is positive at 60 degree of hip flexion when there is lumbosacral pain. ${ }^{14}$

\section{Hip ROM}

The hip abduction and internal ROM rotation were determined with a semi-circle goniometer.

\section{Oswestry Low Back Pain Disability Index (ODI)}

ODI was divided into 10 sections design to assess limitation of various activity of daily living.

\section{Quantitative Measure for Piriformis Tightness} Intra rater reliability analysis for quantitative measures of piriformis tightness was assessed by doing pilot study on 5 subjects. Piriformis tightness was measured by two examiners on same subject at different interval measures was done by using Cronbach's alpha method $(p=000)$.

\section{Procedure}

Patient was given inclined sitting position with back supported on pillow so that hip was flexed below 60 degree. Hip adduction was done; thigh was stabilized by another therapist. Axis of goniometer was placed on midpoint of patella; one arm was placed parallel to tibial shaft and another arm was placed perpendicular to ground and patient was asked to internally rotate hip and range was measured by goniometer.

\section{Treatment Intervention}

Control Group (A)

All the patients were treated with application of moist heat over the piriformis muscle, piriformis muscle stretching ( 5 repetitions with 30 seconds hold) strengthening of hip abductor.

\section{Experimental Group (B)}

All patients were treated with PIR in Muscle Energy Technique: The patient had been in a supine lying position, and also the treated leg was positioned in a hip and knee flexion, so the foot to the contralateral knee laterally lies on the table. The hip flexion angle did not exceed 60 degrees. The therapist places, on the one hand, the contralateral ASIS
(Anterior Superior Iliac Spine) designed to prevent pelvic movement, and, on the other, the lateral flexed knee for resistant abduction to contract piriformis (PIR MET) patient was asked to inhale and isometric resistance to abduction was given for 7 to 10 seconds with 5 repetitions. The initial effort is about 20 per cent of the strength of the patient.

Patients in both the groups were advised to avoid sitting for more than 1 hour at a stretch and to stand and walk every 20 minutes during working hours.

\section{Statistical Analysis}

All statistical analysis was carried out using SPSS 14.0 version of Microsoft Window. Students paired t tests are used to detect group differences. Unpaired t test students were used to reveal the discrepancy between intergroup. Chi square test was used to compare sex difference in both groups.

\section{RESULTS}

\begin{tabular}{|c|c|c|c|c|}
\hline & & $\begin{array}{l}\text { Group A } \\
\text { (Control } \\
\text { Group) }\end{array}$ & $\begin{array}{c}\text { Group B } \\
\text { (Experimental } \\
\text { Group) }\end{array}$ & $\begin{array}{c}P \\
\text { Value }\end{array}$ \\
\hline \multirow{4}{*}{ VAS } & Pre-Treatment & $7.90 \pm 1.64$ & $7.83 \pm 1.59$ & $<0.05$ \\
\hline & Post Treatment & $4.86 \pm 2.09$ & $1.26 \pm 1.65$ & $<0.0001$ \\
\hline & Follow Up & $5.53 \pm 1.94$ & $0.96 \pm 1.51$ & $<0.0001$ \\
\hline & Pre-Treatment & $64.50 \pm 4.61$ & $63.07 \pm 6.77$ & $<0.05$ \\
\hline \multirow[t]{2}{*}{ SLR } & Post Treatment & $71.90 \pm 7.16$ & $67.15 \pm 7.40$ & $>0.0001$ \\
\hline & Follow Up & $69.34 \pm 6.41$ & $67.66 \pm 7.75$ & $<0.05$ \\
\hline \multirow{3}{*}{ ODI } & Pre-Treatment & $18.80 \pm 2.65$ & $18.46 \pm 3.01$ & $>0.05$ \\
\hline & Post Treatment & $29.16 \pm 3.90$ & $33.06 \pm 2.03$ & $<0.0001$ \\
\hline & Follow Up & $28.06 \pm 3.92$ & $33.83 \pm 2.69$ & $<0.0001$ \\
\hline \multirow{3}{*}{$\begin{array}{l}\text { Hip Internal } \\
\text { Rotation ROM }\end{array}$} & Pre-Treatment & $20.16 \pm 2.85$ & $20.03 \pm 2.95$ & $>0.05$ \\
\hline & Post Treatment & $25.90 \pm 5.10$ & $35.43 \pm 3.29$ & $<0.0001$ \\
\hline & Follow Up & $23.10 \pm 3.86$ & $35.05 \pm 2.27$ & $<0.0001$ \\
\hline \multirow{3}{*}{$\begin{array}{l}\text { Hip Adduction } \\
\text { ROM }\end{array}$} & Pre-Treatment & $12.80 \pm 3.63$ & $12.70 \pm 3.32$ & $>0.05$ \\
\hline & Post Treatment & $23.50 \pm 4.25$ & $26.43 \pm 4.51$ & $<0.0001$ \\
\hline & Follow Up & $17.86 \pm 4.18$ & $25.96 \pm 4.49$ & $<0.05$ \\
\hline \multirow{3}{*}{$\begin{array}{l}\text { Piriformis } \\
\text { Tightness }\end{array}$} & Pre-Treatment & $18.80 \pm 2.67$ & $18.46 \pm 3.01$ & $>0.05$ \\
\hline & Post Treatment & $29.16 \pm 3.90$ & $33.06 \pm 2.03$ & $<0.0001$ \\
\hline & Follow Up & $28.06 \pm 3.92$ & $33.83 \pm 2.69$ & $<0.05$ \\
\hline
\end{tabular}

Table 1 shows intergroup comparison of VAS, SLR, and ODI, hip internal rotation, hip adduction ROM and piriformis tightness. There was significant difference on post treatment day and follow-up day in all parameters. Intra-rater reliability analysis for quantitative measure of piriformis tightness was done by using Cronbach`s alpha which was found to be highly significant.

Total 60 PS patients were split into two groups of 30 patients in each group. Patient in control group A were treated with simple stretching of piriformis, hot pack and hip abductor strengthening exercises and patients in experimental group were given PIR MET in group B. Hot pack and ergonomic advice was common for both groups. The outcome measures included i.e. VAS, hip abduction and internal rotation ROM and ODI and piriformis tightness were assessed at baseline and post-treatment sessions (12th day) and follow-up sessions (27 days). All classes were homogenous both in their demographic data and in measurements of baseline outcomes. For finding within group student paired $t$ test were used and student unpaired $t$ test were used for difference among inter-group. Intra rater reliability analysis for quantitative measures of piriformis 
tightness was assessed by doing pilot study on 5 subjects. Piriformis tightness was measured by two examiners on same subject at different interval measures was done by using Cronbach's alpha method which was found to be highly significant.

\section{DISCUSSION}

Results of this study showed that both interventions were effective in improving pain reduction, ROM improvement, piriformis tightness disability. Further post isometric relaxation technique in muscle energy technique was effective in sustaining the effects i.e. relieving pain, disability and tightness for longer period of time. Although both applications have beneficial effect on piriformis tightness the application of post isometric relaxation technique caused loading of Golgi tendon organ which inhibits alpha motor neuron that further leads to relaxation of same muscle and significantly increases in length of muscle fiber. ${ }^{15}$

A study on post isometric relaxation technique in 351 patients who had myofacial pain and hyper tonicity of muscles concluded that $330(94 \%)$ got immediate relief of pain and hyper tonicity. ${ }^{12}$ The author of this study pointed out that increase length of shorten muscle fiber is reason behind pain relief. 16 In present study average range of piriformis tightness in experimental group on baseline was 18.46 which immediately increased to 33.06 at end of $12^{\text {th }}$ day and on follow up same range was maintained in experimental group. However, in control group average base line range was 18.80 which improved to $29.60 \%$ on post treatment day and on follow-up day it was 28.06, this reflected that experimental group gave better results and in shorter duration and last for longer period of time.

A study on post isometric relaxation technique on 40 chronic lumbar pain patients further concluded that 17 patients out of 20 were totally pain free ${ }^{17}$ in present study mean score of low back pain on VAS which is 7.90 on baseline improved to 1.26 on $12^{\text {th }}$ day in experimental group than control which was 7.90 on base line improved to 4.86 on $12^{\text {th }}$ day. On follow up day range was 0.96 in experimental group which was 5.53 in control group concluding that VAS was nearly same on follow up day. ${ }^{12,18}$

PIR technique also has significantly increased range of internal rotation and adduction of hip joint as length of piriformis muscle increased in present study hip internal rotation which was 20.03 on base line improved to 35.43 on post treatment day and remained nearly same on follow up day and in control group baseline score which was 20.16 on baseline improved to 25.90 on $12^{\text {th }}$ day which was 23.10 on follow up day. ${ }^{19}$

The hip adduction range was improved in both groups post treatment, but only the hip adduction range in experimental group were sustained for longer duration which was reflected by the follow-up assessment.

Evidence suggests that piriformis hyper tonicity is responsible for sciatic nerve entrapment which is responsible for sciatic nerve entrapment which is responsible for positive SLR. ${ }^{20}$ Various studies evidences suggest that PIR technique is very useful for hypertonic muscle which intern reduced sciatic nerve compression. In the present study, this increase in range on post treatment day and on follow up day in control group was due to less negative values of SLR. ODI shows significant difference in control and experimental group mean. Above outcomes of our study shows that PIR in MET is effective in relieving pain, increasing ROM, decreasing disability in short duration and its effect last for longer duration.

\section{CONCLUSIONS}

Both muscle energy technique as well as simple passive stretching were effective in reducing tightness and improving ROM, but muscle energy technique gave faster relief of pain improving ROM and decreasing tightness of piriformis and disability and had lasting effects in terms of duration than simple stretching.

Data sharing statement provided by the authors is available with the full text of this article at jemds.com.

Financial or other competing interests: None.

Disclosure forms provided by the authors are available with the full text of this article at jemds.com.

\section{REFERENCES}

[1] Ozaki S, Hamabe T, Muro T. Piriformis syndrome resulting from an anomalous relationship between the sciatic nerve and piriformis muscle. Orthopedics 1999;22(8):771-2.

[2] Jawish RM, Assoum HA, Khamis CF. Anatomical, clinical and electrical observations in piriformis syndrome. J Orthop Surg 2010;5:3.

[3] Porterfield JA. Mechanical low back pain : perspectives in functional anatomy. Philadelphia : W.B. Saunders 1998.

[4] Buijs E, Visser L, Groen G. Sciatica and the sacroiliac joint: a forgotten concept. Br J Anaesth 2007;99(5):7136.

[5] Brodin H. Inhibition-facilitation technique for lumbar pain treatment. Acta Belg Med Phys 1983;6(1):31-5.

[6] Shah SS, Consuegra JM, Subhawong TK, et al. Epidemiology and etiology of secondary piriformis syndrome: a single-institution retrospective study. J Clin Neurosci 2019;59:209-12.

[7] Ardman C, Fishman L. Sciatica solutions - diagnosis, treatment and cure of spinal and piriformis problems. Reprint edition. London: W. W. Norton \& Company 2007: p. 208.

[8] Filler AG, Haynes J, Jordan SE, et al. Sciatica of nondisc origin and piriformis syndrome: diagnosis by magnetic resonance neurography and interventional magnetic resonance imaging with outcome study of resulting treatment. J Neurosurg Spine 2005;2(2):99-115.

[9] Wallin D, Ekblom B, Grahn R, et al. Improvement of muscle flexibility. A comparison between two techniques. Am J Sports Med 1985;13(4):263-8.

[10] Lewit K, Liebenson C. Manipulative therapy in rehabilitation of the motor system. $3^{\text {rd }}$ edn. London: Butterworth-Heinemann 1999: p. 346. 
[11] Magnusson SP, Simonsen EB, Aagaard P, et al. Mechanical and physical responses to stretching with and without preisometric contraction in human skeletal muscle. Arch Phys Med Rehabil 1996;77(4):373-8.

[12] Lewit K, Simons DG. Myofascial pain: relief by postisometric relaxation. Arch Phys Med Rehabil 1984;65(8):452-6.

[13] Boonstra AM, Preuper HRS, Reneman MF, et al. Reliability and validity of the visual analogue scale for disability in patients with chronic musculoskeletal pain. Int J Rehabil Res 2008;31(2):165-9.

[14] Hernández-García R, Gil-López MI, Martínez-Pozo D, et al. Validity and reliability of the new basic functional assessment protocol (BFA). Int J Environ Res Public Health 2020;17(13):4845.

[15] Chen CK, Nizar AJ. Prevalence of piriformis syndrome in chronic low back pain patients. A clinical diagnosis with modified FAIR test. Pain Pract 2013;13(4):276-81.
[16] Parziale JR, Hudgins TH, Fishman LM. The piriformis syndrome. Am J Orthop (Belle Mead NJ) 1996;25(12):819-23.

[17] El Laithy MH, Fouda KZ. Effect of post isometric relaxation technique in the treatment of mechanical neck pain. Phys Ther Rehabil 2018;5(1):20.

[18] Hopayian K, Song F, Riera R, et al. The clinical features of the piriformis syndrome: a systematic review. Eur Spine J 2010;19(12):2095-109.

[19] Smoll NR. Variations of the piriformis and sciatic nerve with clinical consequence: a review. Clin Anat 2010;23(1):8-17.

[20] Bourdillon A, Nicollet M, Parent J. Velocity characteristics of $\mathrm{F}$ region irregularities at sub-auroral latitudes. Geophys Res Lett 1982;9(6):696-9. 